\title{
The Origin, Present Situation and Prospect of Positive Education -- Based on the Perspective of Positive Psychology
}

\author{
Zeng Chen ${ }^{1,2}$ \\ ${ }^{1}$ School of Foreign Languages, Yancheng Teachers University, Yancheng, China \\ ${ }^{2}$ College of Teacher Education, Zhejiang Normal University, Jinhua, China
}

Email address:

438673437@qq.com

\section{To cite this article:}

Zeng Chen. The Origin, Present Situation and Prospect of Positive Education -- Based on the Perspective of Positive Psychology. International Journal of Education, Culture and Society. Vol. 3, No. 2, 2018, pp. 28-33. doi: 10.11648/j.ijecs.20180302.12

Received: April 23, 2018; Accepted: May 8, 2018; Published: May 28, 2018

\begin{abstract}
The positive education oriented by positive psychology emphasizes starting from the individual's strengths, guiding participants' positive experiences, and ultimately increasing the teachers and students' sense of gain. That is to say, on the one hand, positive education should improve the subjective experience of teachers and students, make them feel good; on the other hand, make the teachers and students have meaningful value, and feel their positive qualities or advantages have been enhanced. Positive education breaks through the traditional education's parochialism on having a bias toward trouble-solving. It not only is a supplement to traditional education under the new social background, but also the repositioning of education after deeply understanding the value of education, which provide a new idea for the contemporary education reform and innovation.
\end{abstract}

Keywords: Positive Education, Positive Psychology, Sense of Gain, Strengths-Oriented Development

\section{Introduction}

Whenever a school is mentioned, people usually think that the school is a place to transmit wisdom, impart knowledge, and resolve doubts. Students come to school to learn and accept knowledge. However, since ancient times, there has been such a saying as "on the pillow, on the horse, and on the toilet" ("three on"), which seems to suggest that wherever and whenever he can learn, the school is not the only place for learning. Moreover, with the rapid development of science and technology, the popularization of network schools and the emergence of artificial intelligence, the education methods and media are increasingly diversified. The acquisition of knowledge and the development of education are becoming easier and easier. The value of the existence of school seems to be questioned. At the same time, since ancient times, Chinese traditional culture has always advocated as follows: "Diligence is the path to the mountain of knowledge, hard-working is the boat to the endless sea of learning", making school education left a bitter stereotyped impression. The end of each holiday is considered to be the end of happiness by many students. Although inspirational diligent study is certainly necessary, why can't we bring it some sunshine? Why not let students learn in happiness, appreciate happiness and achieve sense of gain to realize the self worth? Many people can't help asking: what is the purpose of students' coming to school? Positive education may provide a new way of thinking for this issue.

\section{The Origin of Positive Education}

\subsection{The Connotation and Theoretical Basis of Positive Education}

Positive education refers to an educational concept that aims to increase its sense of gain by taking individual potential as its starting point, adopting positive educational actions, and guiding and inspiring the positive experience of educational participants. The word "positive" is easily to be misled. In fact, it refers to the subjective feeling. Its meaning is relative, not a fixed result and the final outcome. Positive is a behavioral process, including cognition, emotion and other aspects of experience. Positive is a guiding concept rather than a scientific concept. A man with a fatal illness and a writer in a 
state of creation, although facing different states of life, they may all be positive because of their senses of gain. The former is the courage to survive in the fight against disease, while the latter is to obtain the passion of life due to the experience of creative peak. Therefore, it is related to the individual's situation and can only be compared from diachronic dimension, which refers to the individual's choice of the most adaptable environment and the behavior that exerts the highest potential. [1] And the "sense of gain" emphasized by positive education pays more attention to the fair and impartial "objective acquisition" in education to increase the actual effect of individual self-realization, and achieve the unification of subjective and objective evaluation, which surpasses the subjectivity of general education quality evaluation.

The emergence of positive education is closely related to positive psychology. The term "positive psychology" first appeared in 1954 in the book «Motivation and Personality» of Maslow, an American psychologist. After the end of World War II, aimed at quickly curing people's psychological trauma caused by the war, psychological research focused on the pathological perspective, to explore how and why people struggled; and the vast majority of research work is aimed at "problem people". It is a remedy for the negative attributes of humans, rather than promoting understanding of the positive attributes of humans. At the end of the 20th century, under the advocacy of Martin Seligman, President of the American Psychological Association, positive psychology developed into a new trend of psychology. It points out: "The goal of positive psychology is to catalyze the shift in the focus of psychology, from focusing only on repairing bad things in life to taking into account the cultivation of the positive qualities of human beings." [2] Positive psychology also emphasizes that the positive attribute of human beings is not only a tool to remedy the negative attribute, and the individual strength should be used as the fundamental goal of their development. Any individual has its unique ability to adjust, adapt, understand and actively absorb the "strength" in the changing environment. This is an inevitable response mechanism in the process of human evolution. Through this adaptation, people can obtain physiological and psychological well-being. [3]

There are many similarities between education and positive psychology. The ultimate goal of both is to promote the overall healthy development of human beings. It is embodied in three main tasks: Firstly, it corrects the shortcomings of people, help the problematic people to analyze the problems and eliminate the problems; secondly, it makes people more productive and ethical, and accomplishes the self realization of the people from the biological sense to society; thirdly, the genius is fully developed on the basis of identifying people. [4] Therefore, according to the value orientation of positive psychology, positive education came into being.

\subsection{Positive Education Is an Inevitable Result of the Development of the Times}

It cannot be denied that traditional education centered on problems plays an important role in promoting the overall quality of the entire people. Nowadays, with the rapid development of the entire society, it is not enough to emphasize too much on correction of the individual that belongs to the instrumental value of education, which violates the original and ultimate value of education. The concept of positive education centered on the sense of gain has made up for the lack of education in this perspective. Education should have an epochal and forward-looking vision, be people-centered, and lay the foundation for the individual's lifelong development and the pursuit of a lifetime of happiness.

First of all, from the perspective of student development, this "pathological" type of traditional education that over-emphasizes problem correction has made it very restrictive to promote many positive strengths and functions of individual development, such as self-improvement, self-motivation, etc. It will even result in learned helplessness. And these positive factors are of great significance to individuals. The "expansion - construction" theory of positive emotions proves that individuals in positive emotions will expand their behavior tendency in a particular situation, which is beneficial to them to construct sustainable development resources and generate more creativity [5]. Positive education starts from the perspective of strength, and strives to create positive experience of individuals, which is conducive to the formation of optimistic explanatory style. Moreover, the emphasis on sense of gain also helps individuals to further affirm their own abilities, so that they can view their problems and cognize themselves more rationally.

Secondly, from the perspective of teacher development, under the traditional education model that aims at correcting mistakes and focuses on repairing, the main task of teachers is to find out students' problems and find a mechanism or method to solve them. In the eyes of teachers, there are only students' problems, and students are naturally inconsistent and indifferent to the teachers, let alone emotional resonance. Teachers can not feel the sense of mission and value from the teaching process. In the long run, they will lack interest in teaching and cause occupational burnout. Positive education advocates paying attention to the strengths of individuals and making students' knowledge seeking process a positive process. During the process of education, the students' sense of gain will undoubtedly bring a constant source of driving force to their further self realization, which makes the educators firmly believe that educating is a career of realizing their self-worth, and feel the lofty meaning and responsibility of their own life. At the same time, positive education also believes that teaching is a process in which teachers and students participate together to gain positive experiences. This undoubtedly also brings the relationship between them closer. Not only can it help teachers to relieve the pressure of work and life, but also can enhance their physical and mental health to contribute to their career development.

Finally, from the point of view of social development, when education can only cover a few privileged classes, the problems that urgently need education to solve are widespread and universal. The effect of traditional education on 
improving the overall quality of the population and the degree of socialization is obvious. Nowadays, the socialization function of education has achieved remarkable results, and education has entered the stage of popularization and even popularization. We should be more people-oriented, emphasizing the promotion of education for individual self-realization.

With the rapid development of various disciplines, the rapid growth of knowledge is caused, and the increasing diversification of educational methods and transmission media, the acquisition of knowledge and the development of education have also become very easy. The education ecology of the whole people has been greatly improved, and the school education can not only pay attention to the basic knowledge and gain. We should pay more attention to the individual's sense of participation in educational activities, and the resulting sense of gain, and the sense of gain here does not emphasize a sense of unity, but a sense of diversity. There is also a trend in the development of society: When a certain society has reached a stable state of relative prosperity, civilization, and prosperity, people and the entire society are no longer confined to the most basic requirements, and they are bound to pay more attention to the positive side. At present, the educational environment of human beings has been greatly improved compared to the past. The purpose of human education is no longer to master simple survival skills but to gain a sense of self realization. Naturally, we should pay more attention to the positive factors of education. In such a relatively prosperous state of civilization, the traditional education centered on the elimination of problems seems to be out of place. The emergence of positive education makes up for the lack of current education and also conforms to the development trend of society.

\section{The Present Situation of Positive Education}

\subsection{Positive Education Is Not a Complete Negation of Traditional Education, But a Supplement}

Positive education not only promotes the basic function of education - "to be intelligent and reasonable", but also breaks through the narrowness of traditional education overemphasizing the problems-solving. Therefore, it has high application value. As Nel Noddings, the founder of the American Care Education Theory, said, "happiness and education should be closely linked: the goal of learning should be to obtain happiness, and a good education itself should have an important positive impact on the level of individual and group happiness." From this perspective, positive education provides a new way of thinking for contemporary education reform and innovation. [6]

\subsubsection{Harmfulness of the Single Value of Traditional Education}

For a long period of time, correcting problems seems to have become the sole task of traditional education. Educators are always accustomed to using problematic perspectives to help students recognize their deficiencies through criticism, so as to achieve the ultimate goal: correcting students' various explicit or implicit shortcomings and problems. The unitary nature of educational values allows educators to calmly help students in distress to change and live well. However, in the face of students who are already in good conditions, they seem to be at a loss and do not know how to make them better, which leads to the imbalance of education itself. The single corrective skills of educators make them have only problems in their eyes but no students. This traditional education is essentially a kind of pathological education, showing typical non-humanized characteristics. Under such circumstances, students' learning has correspondingly become a negative adaptation that has to be generated due to external pressure. The problematic value orientation of traditional education has also led to the overflow of educational problems. The problems of the students are amplified by the utilitarian, which has made students have a sense of inexplicable fear of the school. They think that the school is like a hospital, where they seem to be a collection of problems and waiting for being cured passively. It leads to a serious lack of well-being and sense of gain brought by self- value realization. The relationship between students and teachers has also generated an insurmountable gap, resulting in teachers' sense of occupational identity less and less, which in turn causes occupational burnout. [7].

\subsubsection{Differences and Connections Between Positive Education and Traditional Education}

Traditional education overemphasizes the function of correction, with the main task of finding and solving problems. While positive education is committed to the individual's potential, to increase participants' sense of gain as the core, and to guide them to positively surpass the ego, so these two are different in the perspective of education. The traditional education believes in the theory of external control. It is believed that as long as we refer to certain standards, the problem of individual is found enough and the solution is thorough enough, the individual will promote himself and develop its own educational effect under the drive of the outside world. [8] Therefore, traditional education pays more attention to the immediacy, explicit effect and instrumental value of education, adopts the pathological paradigm to correct the problems of the individual in order to improve the overall quality of the whole people, which may have some effect in a short time. However, because the issues they are concerned with are external, non-essential, and uncontrollable, as well as most individuals accept passively and cannot gain lasting development momentum. The positive education emphasizes the discovery of the student's strength and is committed to creating a condition conducive to the strength's development. It believes that even if we solve more and more individual problems, it is only externally forced to make temporary provision. Individuals are self-conscious and will not accept passively as permanent machines. They need self-control. Only when individuals can experience and satisfy 
the inner needs through education, they will continue to carry it on actively and continuously. This motivation is the sense of gain produced by the individuals in the process of positive education. The traditional education is accustomed to starting work from student's problem, which leads to the focus of attention on the "two ends", that is, the underachiever and the top student. In teacher's mind, the underachiever is "problem student", and the top student is afraid of being in "problems" and thus ignores the concern of many middle-class students. Positive education emphasizes that all aspects of every student should be focused on. It should not be limited to helping problematic students or finding and solving all kinds of problems in students. Efforts should be made to treat each student equally, give attention to those students without problems and develop their strengths. However, these two are not completely opposed to each other, but have different perspectives on education. The author believes that traditional education and positive education have many mutual references and promotions in many aspects. The purpose and task of positive education and traditional education are both to promote people to become physically and mentally healthy people who meet the requirements of social development. However, the focus of each one is different respectively, resulting in a certain degree of differences in educational content and methods, as well the results of each education are not same. Therefore, positive education and traditional education are intrinsically linked. Positive education is not only a supplement to traditional education, but also a repositioning of education after a thorough understanding of traditional education. Therefore, in education, we must not only help problematic individuals or resolve various problems in them, but also help those who have no problems develop their strengths so as to increase sense of gain, achieve self-fulfillment, and become the best of themselves.

\subsection{The Concept of Positive Education Meets the Requirements of China's Current Basic National Conditions}

At present, China is undergoing a period of social transformation. The main problems faced during the reform process are different in different periods, and the development focus is also different. The evaluation criteria must keep pace with the times and constantly give new connotations. The report of the Nineteenth Congress put forward an important conclusion: Socialism with Chinese characteristics has entered a new era. The major social contradictions in our country have been transformed into the contradiction between the people's ever-growing needs for a better life and unbalanced development. The key to the development of the country is to meet the needs of the people's material life and continue to meet the needs of people's diverse 、 individualized and spiritual rights. Therefore, as far as education is concerned, on the basis of continuous development, it will shift from a high-speed growth phase to a high-quality development phase. Since the reform and opening up, while China's education has achieved brilliant achievements in rapid development, it has also accumulated a large number of contradictions, leading to unbalanced and inadequate development. In response to the various problems faced by the country, the country advocates "sharing" development concepts and exerting group strengths. Its fundamental goal is to improve people's sense of gain. The positive education centered on increasing teachers and students' sense of gain conforms to our country's adherence to the people-centered development orientation. China is a country of people's democratic dictatorship, and the support of people is the source of development and the foundation of victory. Therefore, people's sense of gain is not only the purpose of reform, but also the criterion for testing the effectiveness of reform. Therefore, "letting individuals have more sense of gain" is not only a demand for a new round of deepening education reform, but also the deepest hope of the broad masses of people.

\section{The Prospect of Positive Education}

\subsection{Positive Education Clearly Defines Two Major Functions of Education: Elimination of Problems and Development of Strengths, Namely Cold Function and Warm Function}

Positive education believes that education cannot focus solely on the analysis of individual negative consequences, but rather on its positive resources. This redefines the function of education: it includes both the cold function of eliminating problems and the warm function of developing strengths. Education should be balanced, with equal emphasis on problem solving and strength development. Problem and strength are two independent variables. Therefore, it is not enough for traditional education to devote too much effort to solving problem. There is a certain degree of correlation between these two, but there is no certainty. Strength is not the subsidiary result after the problem is resolved. The resolution of the problem does not necessarily mean the emergence of strength. The development and growth of an individual mainly depend on the accumulation of strength rather than the resolution of problem. The solution to the problem is only temporary and non-essential, and the formation of the positive quality contributed by the accumulation of its strength is long-lasting, essential, and decisive. At the same time, there is a question of appropriateness in the handling of problems. Everything has two sides, not all the problems can be solved. If some problems are solved, their associated strengths will also disappear. In fact, the development of some human negative qualities always has its own specific functions. For instance, jealousy can weaken the individual's own happiness, but it is one of the sources of human initiative. Positive education believes that sometimes for education the importance in preserving some of the students' shortcomings is far greater than the overcoming of these shortcomings. [9]

\subsection{Positive Education Should Focus on Increasing the Sense of Gain of Teachers and Students}

In terms of literal meaning, "sense of gain" is the subjective 
feeling of "gain". It is based on "objective acquisition", belongs to subjective perception of "objective acquisition". [10] And the "sense of gain" involved in positive education should be based on real harvest, not only the acquisition of knowledge and the solution of the problem, but also the power to participate in the classroom, the right of expression, the right to choose the content, and the right of self control in the direction of development. The "sense of gain" in positive education must be characterized by fairness and justice. It is not limited to the individual's sense of gain, but an integrity one, ensuring that every member in education can share self-realization fairly and impartially. Therefore, the "sense of gain" is not only about the feeling of "absolute gain", but also the "relative sense of gain". The "sense of gain" has made clear the goal, direction, breakthrough of educational development and reform. The ultimate purpose of education is to promote individual's self-development and self-realization. Solving problems passively is only driven by temporary external forces. Exerting individual strength and an endless "sense of gain" is the fundamental driving force for its development. The "sense of gain" has also solved the problem of the education development's quality and the evaluation criteria for the success or failure of reforms. We cannot simply equate it with "well-being". There is a certain degree of similarity between these two. Both can evaluate the effectiveness of education's implementation, but the latter emphasizes subjective perception, and the subjective feeling to evaluate the effect of the objective reform is lack of rigor. The "sense of gain" can be embodied in a series of teaching-related indicators, such as knowledge quantity, participation and so on. The increase or not of teachers' and students' "sense of gain" is the ultimate criterion for measuring the quality of education development. It is clear that the evaluation subject is all participants, the evaluation content is "objective gain", and the evaluation criterion is "subjective feeling", which avoids the antagonism between teachers and students, contains the differences among individuals, and can lead the education reform more scientifically and effectively. [11]

\section{Conclusion}

In the process of implementing positive education, we should pay attention to the following issues:

First of all, positive education does not negate the traditional education centered on overcoming or correcting students' shortcomings. But the emphasis of education is different from each other. Positive education is a supplement to traditional education, and a sublimation of traditional education. On the one hand, students should correct their problems, and on the other hand, increase their own strengths. Secondly, positive education is not what we used to be to promote advantages and overcome shortcomings. It emphasizes the warm function of education, and should devote itself to the discovery, cultivation and accumulation of individual strengths in order to promote the individual's true growth. The role played by the overcoming of shortcomings in the individual development is only temporary and palliative, as antibiotics can be used to treat diseases, but cannot strengthen the body. Moreover, the development of the advantages is only a specific method of positive education, and the positive education involves many aspects, such as educational methods, ways, contents, and evaluation. Besides, positive education not only concerns the well-being of teachers and students, but is essentially a gaining education. The sense of well-being is a kind of experience gained by people's comprehensive evaluation of the quality of education according to their own standards. It tends to emphasize the individual subjective perception, so it is more likely to flow into vagueness. [12] The "sense of gain" cannot exist without its "objective gain" basis, and is more specific and practical. Therefore, when evaluating the development and change brought about by education, it is real and sensible to use the "feeling of gain" as a measure. At the same time, positive education centered on increasing teachers' and students' sense of gain can allow us to expect to witness the achievements of education reform and to release individual self-realization motivation in more "sense of gain". Finally, positive education is a scientific practice that conforms to the laws of human brain activity and is an education that accords with the laws of psychological science. Therefore, we should combine the research results of positive psychology with positive education. Under the guidance of positive psychological research results, we should find out and master the laws of individual physiological and psychological changes and development, clear the training objectives of every stage of positive education, and provide psychological basis for the selection of educational content and method. [13]

\section{Acknowledgements}

The work is supported by the Youth Research Programs for Humanities and Social Sciences "Positive Education from the Perspective of Educational Warm Function" in Yancheng Teachers University in 2017 (17YCSK015), the"13th Five-Year Plan" Special Project of Education Science in Jiangsu Province and the Project of University Philosophy and Social Sciences Research Fund in Jiangsu Province.

\section{References}

[1] Chen Zhenhua. The Outline of Positive Education [J], Journal of East China Normal University (Education Science), 2009, (3).

[2] Seligman E. P, and Csikszentmihalyi M. Positive Psychology: An Introduction [J]. American Psychologist, 2000, 55 (1): 5-14.

[3] Peterson C, Seligman M E P. Character Strengths and Virtues: A Handbook and Classification (New York: American Psychological Association \& Oxford University Press, 2004) [J]. American Journal of Psychiatry, 2012, 162 (4):419-421.

[4] Ren Jun. Positive Psychology [M], Shanghai:Shanghai Education Publishing House, 2006: 132-134. 
[5] Fredrickson B L. The Role of Positive Emotions in Positive Psychology: The Broaden-and-Build Theory of Positive Emotions [J]. American Psychologist, 2001, 56 (3):218-26.

[6] Marks, L. I, \& Wade, J. C. Positive psychology on campus: Creating the conditions for well-being and success. About Campus, 2015, (6): 9-15.

[7] Noble. T, \& McGrath, H. Prosper: A new framework for positive education [J]. Psychology of Well-being, 2015, 5 (1):1-17.

[8] Norbert Wiener. Cybernetics [M], Beijing:Science Publishing House, 1963: 67-68.

[9] Ren Jun. A Probe into the Western Positive Education Thoughts [J]. Studies in Foreign Education, 2006, (5).
[10] Ding Yuanzhu. Let the Residents Have the Sense of Gain to Get Through the Last Mile -- the Practice Path of Community Governance Innovation in the New Era [J], State Governance, 2016, (2): 18-23.

[11] Bryk A S, Schneider B. Trust in Schools: A Core Resource for Improvement [M]. New York: Russell Sage Foundation, 2002.

[12] Seligman MEP, Ernst RM and Gillham J. Positive education: positive psychology and classroom interventions [J]. Oxford Review of Education, 2009, 35 (3):293-311.

[13] Noël Williams. The Impact of Positive Psychology on Higher Education. Impact of Positive Psychology, 2018, (1):83-94. 